\title{
Wind Loading on a Hyperbolic Paraboloid Free Roof
}

\author{
Yasushi Uematsu $^{1}$, Yukari Miyamoto ${ }^{2}$ and Eri Gavansky ${ }^{1}$ \\ 1. Department of Architecture and Building Science, Graduate School of Engineering, Tohoku University, Sendai 980-8579, Japan \\ 2. Kume Sekkei Co. Ltd., Tokyo 135-8567, Japan
}

\begin{abstract}
Wind loading on an H.P. (hyperbolic paraboloid) free roof has been investigated on the basis of a wind tunnel experiment. The roof models of $1 \mathrm{~mm}$ thickness were made of nylon resin using laser lithography. The parameters under consideration are the rise to span ratio and slope of the roof. The overall aerodynamic forces and moments were measured by a six-component force balance in a turbulent boundary layer. Based on a combination of the lift and moment coefficients, the design wind force coefficients, $C_{N W}{ }^{*}$ and $C_{N L}{ }^{*}$, on the windward and leeward halves of the roof are proposed. Focus is on the column axial forces induced by wind loading as the load effect for discussing the design wind loads, assuming that the roof is rigid and supported by four corner columns. Indeed, two pairs of $C_{N W}{ }^{*}$ and $C_{N L}{ }^{*}$, generating the maximum tension and compression in the columns, are provided for each of the two or three wind directions parallel to the roof's diagonal lines. The proposed values of the wind force coefficients are compared with the specified values in the Australia/New-Zealand Standard for a limited range of rise to span ratio.
\end{abstract}

Key words: Free roof, hyperbolic paraboloid, wind force coefficient, wind tunnel experiment, codification.

\section{Introduction}

H.P. (hyperbolic paraboloid) free roofs are widely used for structures providing shade and weather protection in public spaces, such as sports grounds and shopping areas. Pre-tensioned membrane is often used for such roofs. The roofs are consequently very lightweight structures that are vulnerable to wind actions. In practice, such roofs often experience damage during windstorms. Therefore, the wind resistance is one of the greatest concerns for structural engineers when designing these roofs. However, few specifications of design wind loads on H.P. free roofs are provided in building codes and standards. Although the AS/NZ (Australia/New Zealand) Standard [1] provides the wind force coefficients, the range of roof geometry is rather limited.

Since free roofs are usually supported by columns and no walls exist, wind action is directly exerted both on the top and bottom surfaces. Consequently, the flow around the roof is rather complicated. Whereas, a large

Corresponding author: Yasushi Uematsu, professor, research field: architectural wind engineering (wind effects on buildings and structures, wind environment, wind power generation, etc.). E-mail: yu@archi.tohoku.ac.jp. database of knowledge exists for wind pressure distributions on enclosed buildings of various shapes, e.g., Dutt [2-4], only a few studies have been made on the wind loading on free roofs [5], which may be due to difficulties in model making and wind pressure measurement.

Uematsu et al. [6] proposed the design wind force coefficients both for the main wind force resistant systems and for the $\mathrm{C} \& \mathrm{C}$ (cladding and components) of planar free roofs based on a series of wind tunnel experiments. They made simultaneous pressure measurements for gable, troughed and mono-sloped roofs in a turbulent boundary layer. They focused on the axial forces induced in the columns as the load effect for discussing the design wind loads, assuming that the roof was rigid and simply supported by four corner columns.

In addition to such basic shapes that Uematsu et al. [6] tested, H.P. roofs are often used for membrane structures. Beutler [7] measured the mean wind pressures on H.P. free roofs. Regarding the wind-induced response of H.P. free roofs, Pun and Letchford [8] reported the analytical results of an H.P. tension membrane roof subjected to fluctuating wind 
loads. Recently, Kaseya et al. [9] measured the distribution of wind force coefficients on an H.P. free roof in a turbulent boundary layer. Using the time history of wind force coefficients at 25 points on a rigid model obtained from the wind tunnel experiment, Nakagawa et al. [10] investigated the dynamic response of membrane roofs. The thickness of the wind tunnel models was $5 \mathrm{~mm}$, while the length of the side was $100 \mathrm{~mm}$. The models were so thick that the flow around the models seemed to be distorted [11, 12].

To the authors' best knowledge, no study has been made on the design wind loads on H.P. free roofs with a wide range of roof geometry. Simultaneous pressure measurements at many points both on the top and bottom surfaces are quite difficult for H.P. free roofs because of the difficulties in model making and pressure measurement. In the present study, therefore, a force balance technique is employed.

The present paper discusses the wind force coefficients for designing H.P. free roofs on the basis of a wind tunnel experiment with rigid models. The overall aerodynamic forces and moments are measured by a six-component force balance in a turbulent boundary layer. The basic idea for specifying the wind force coefficients is the same as that the authors used for the gable, troughed and mono-sloped roofs [6]. The proposed wind force coefficients are compared with the specifications of the Australia/New Zealand Standard. A comparison is also made from the viewpoint of load effect.

The roof deflects and oscillates under wind loading,

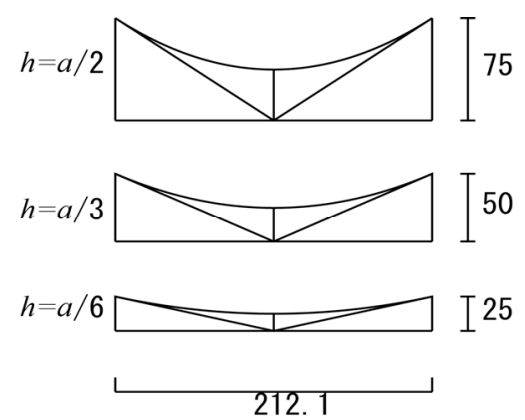

(a) which may affect the wind forces on the roof due to flow-structure interaction. However, as the first step of study, this effect is neglected in the present paper. Takeda et al. [13] have recently made a brief discussion on the effect of mean deformation of H.P. membrane roofs on the mean wind forces using a CFD (computational fluid dynamics) analysis. It should be mentioned that the present paper is a revised and advanced version of the authors' previous papers $[14,15]$, focusing on the design wind force coefficients.

\section{Experimental Arrangement and Procedures}

The experiments were carried out in a turbulent boundary layer with a power law exponent of $\alpha=0.21$ for the mean velocity profile. Three models with different rise to span (or sag to span) ratios were made of nylon resin using laser lithography (Fig. 1). The thickness of the roof models was $1 \mathrm{~mm}$. The notation and coordinate system used in the present paper are shown in Fig. 2. The lift $L$, positive upward, and the aerodynamic moments $M_{x}$ and $M_{y}$ about the $x$ and $y$ axes were measured by a six-component force balance (SSKLBW60-1). They are reduced to coefficients as follows:

$$
\begin{aligned}
& C_{L}=\frac{L}{q_{H} S} \\
& C_{M x}=\frac{M_{x}}{q_{H} S a^{\prime}} \\
& C_{M y}=\frac{M_{y}}{q_{H} S a^{\prime}}
\end{aligned}
$$

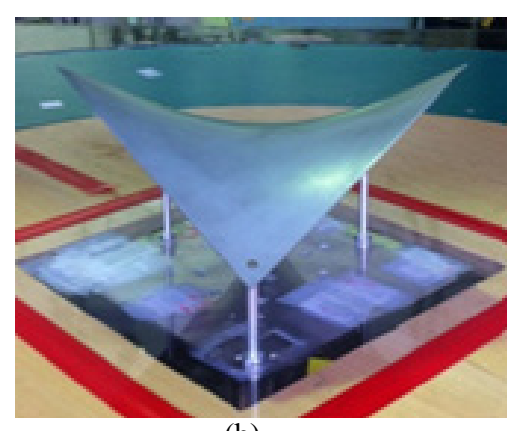

(b)

Fig. 1 Experimental models: (a) shape and dimension (mm); (b) wind tunnel model with $h / a=1 / 2$. 


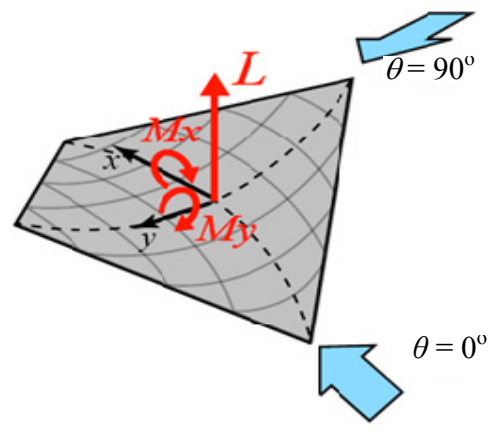

(a)

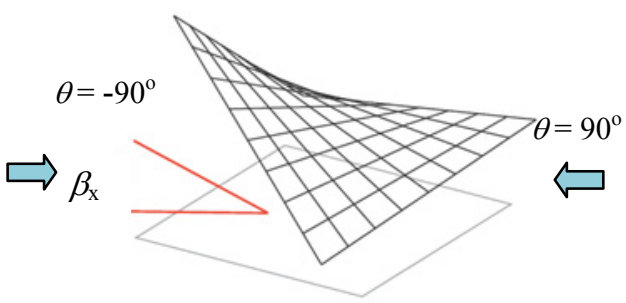

(b)

Fig. 2 Notation and coordinate system: (a) aerodynamic force and moments; (b) roof slope.

where, $q_{H}=$ time-averaged velocity pressure of the flow at the mean roof height $H(80 \mathrm{~mm}) ; S=$ projected plan area of the roof $\left(a^{2}\right)$ and $a^{\prime}=(\sqrt{2} / 3) a$, which is used as a reference length of the models; $a=150 \mathrm{~mm}$. The roof slope $\beta_{x}$ obtained by rotating the roof about the $x$-axis was changed from $0^{\circ}$ to $40^{\circ}$. The wind direction $\theta$ was changed from $0^{\circ}$ to $90^{\circ}$ for $\beta_{x}=0^{\circ}$ and from $-90^{\circ}$ to $90^{\circ}$ for $\beta_{x}>0^{\circ}$.

The measurements were carried out at a wind velocity of $U_{H} \approx 9 \mathrm{~m} / \mathrm{s}$ at the mean roof height $H$. The turbulence intensity $I_{u H}$ at this height was approximately 0.17 . The geometric scale $\lambda_{L}$ and the velocity scale $\lambda_{V}$ were assumed $1 / 100$ and $1 / 3$, respectively, resulting in a time scale of $\lambda_{T}=1 / 33$. The outputs of the force balance were sampled simultaneously at a rate of $200 \mathrm{~Hz}$ for a period of $19 \mathrm{~s}$, which corresponded to $10 \mathrm{~min}$ in full scale. The measurements were repeated six times under the same condition. The statistics of the aerodynamic coefficients were evaluated by applying ensemble average to the results of these six consecutive runs. The wind forces on the three legs of $5 \mathrm{~mm}$ diameter supporting the roof were measured separately and were subtracted from the overall loads to produce load on the roof alone.

The Reynolds number $R e$, defined in terms of $U_{H}$ and $a$, is approximately $9 \times 10^{4}$. The great concern is the Reynolds number effect on the aerodynamics, because the H.P. free roof consists of curved surface. The Reynolds number effect is related to the change in location of flow separation point on the curved surface. The results of flow visualization using oil-film method [15] and CFD analysis [16] indicate that the wind flows along the top surface of the roof when $\theta=0^{\circ}$, the flow does not separate from the top surface even when $h / a=1 / 2$. Regarding the bottom surface, the flow separates at the leading edge of the roof and generates conical vortices on the bottom surface. From these results, the Reynolds number effect seems small for H.P. free roofs under consideration here.

\section{Experimental Results}

\subsection{Wind Forces on Roofs with No Slope}

Fig. 3 shows the statistical values of $C_{L}, C_{M x}$ and $C_{M y}$ as a function of wind direction $\theta$ for $h / a=1 / 2$. The mean, maximum and minimum peak values of these aerodynamic coefficients are plotted in Fig. 3. The lift coefficient $C_{L}$ becomes the maximum (upward) when $\theta \approx 0^{\circ}$ and the minimum (downward) when $\theta \approx 90^{\circ}$. This feature is related to the increased wind velocity along the convex surface, i.e., the top surface when $\theta \approx$ $0^{\circ}$ and bottom surface when $\theta \approx 90^{\circ}$. The magnitude of the negative peak value of $C_{M x}$ becomes the maximum when $\theta \approx 90^{\circ}$, while that of $C_{M y}$ becomes the maximum when $\theta \approx 0^{\circ}$. The absolute values of $C_{M x}$ for $\theta \approx 0^{\circ}$ and those of $C_{M y}$ for $\theta \approx 90^{\circ}$ are relatively small. The variation of $C_{M x}$ with $\theta$ is opposite to that of $C_{M y}$. Almost the same features were observed for $h / a=1 / 3$ and $1 / 6$. Furthermore, it was found that the magnitude of the maximum and minimum peak values increases with an increase in $h / a$. 
The axial forces $N$ induced in the columns were computed by using the time history of $C_{L}, C_{M x}$ and $C_{M y}$ obtained from the wind tunnel experiment, assuming that the roof was rigid and simply supported by four corner columns. In the present study, focus is on the axial forces induced in the columns as the load effect for discussing the design wind loads. The maximum and minimum peak values of the non-dimensional axial forces $N^{*}=N /\left(q_{H} S / 4\right)$ among the four columns are plotted in Fig. 4. Noting that the non-dimensional axial forces induced in the four columns are represented by $N_{a}{ }^{*}$ to $N_{d}{ }^{*}$ (Fig. 4e). As might be expected from the results in Fig. 3, the peak values of $N^{*}$ are large in magnitude when $\theta \approx 0^{\circ}$ and $90^{\circ}$. However, this is not always the case. The maximum peak values are induced in oblique winds in some cases.

These experimental results imply that the fluctuating wind forces on the roof are mainly caused by the turbulence in the approach flow. The design wind loads can be specified as the equivalent static loads, in which the dynamic load effect is considered in the evaluation of gust effect factor. The basic values of the wind force coefficients can be specified based on the results for $\theta$ $=0^{\circ}$ or $90^{\circ}$, which should be modified by considering the effect of wind direction on the load effect.

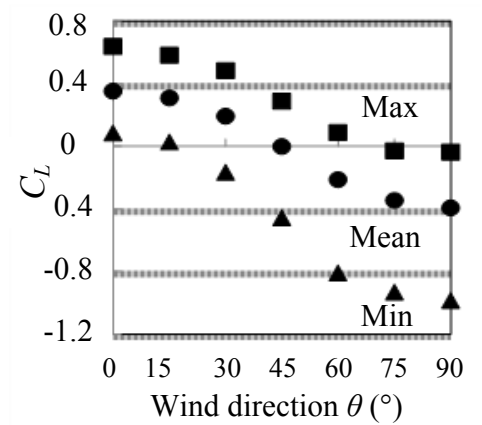

(a)

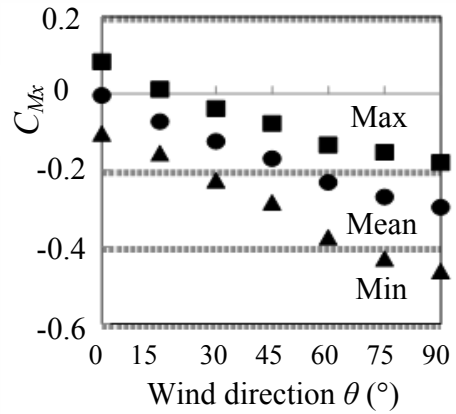

(b)

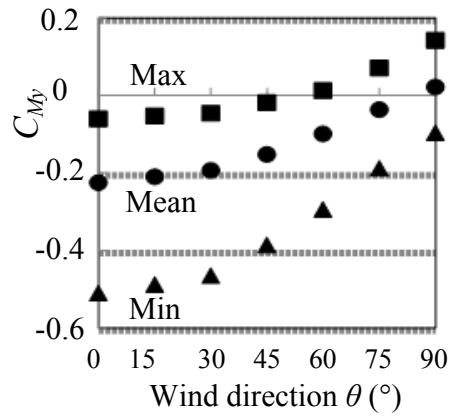

(c)

Fig. 3 Variation of the aerodynamic coefficients with $\theta\left(h / a=1 / 2, \beta_{x}=0^{\circ}\right)$ : (a) $C_{L}$; (b) $C_{M x}$; (c) $C_{M y}$.

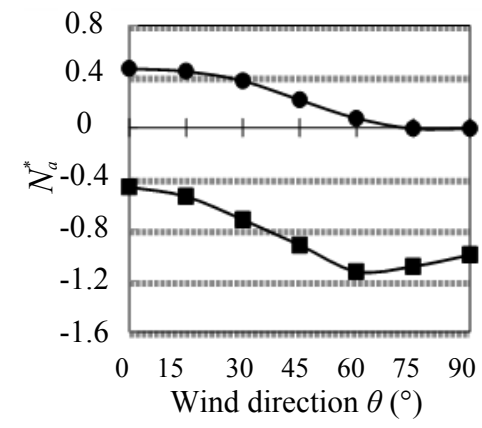

(a)

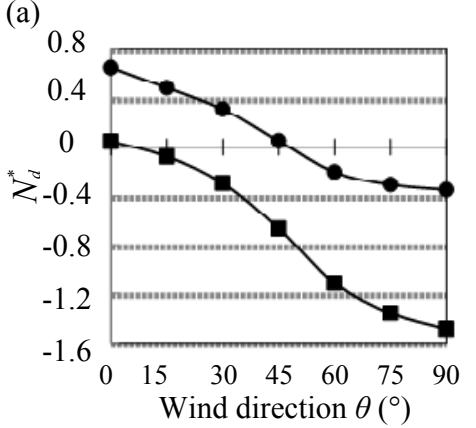

(d)

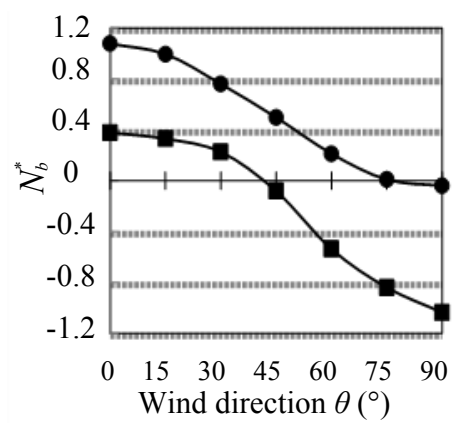

(b)

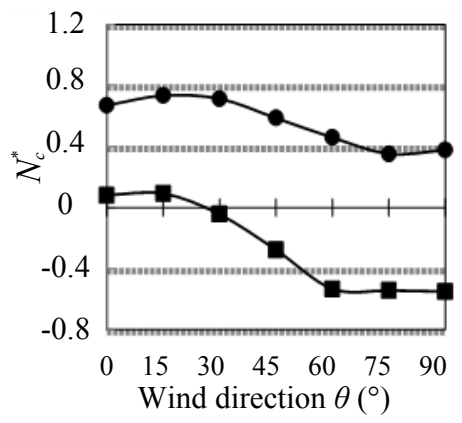

(c)

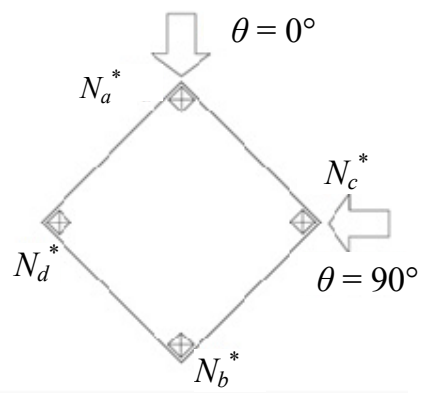

(e)

Fig. 4 Variation of non-dimensional axial forces $N_{a}{ }^{*}$ to $N_{d}{ }^{*}$ with $\theta\left(h / a=1 / 2, \beta_{x}=0^{\circ}\right):$ (a) $N_{a}{ }^{*}$; (b) $N_{b}{ }^{*}$; (c) $N_{c}{ }^{*}$; (d) $N_{d}{ }^{*}$; (e) notation of axial forces. 


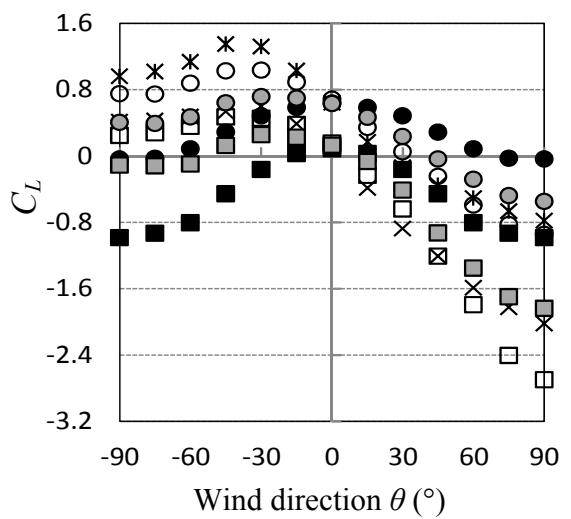

(a)

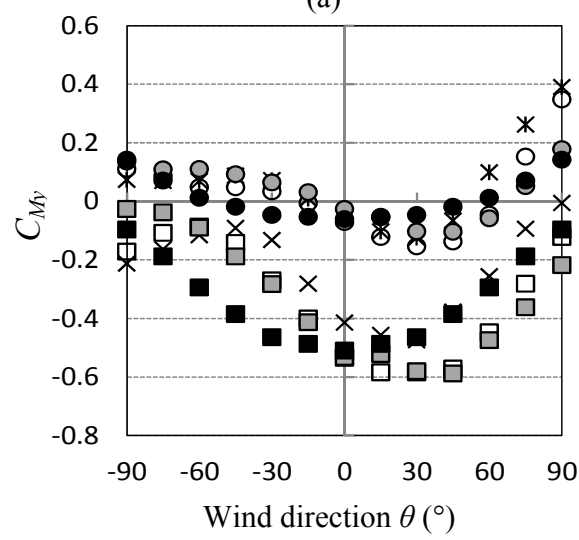

(c)

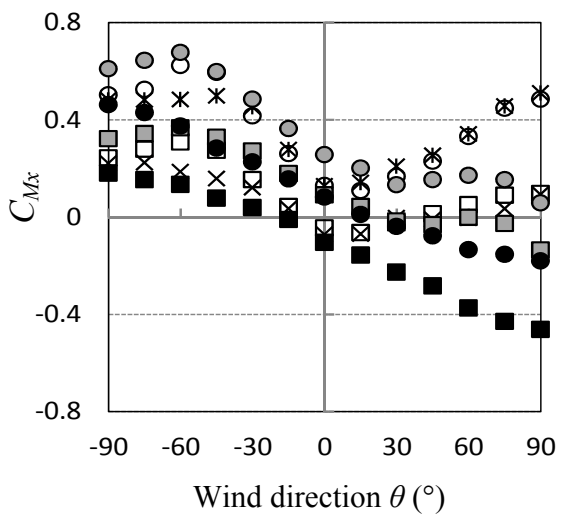

(b)

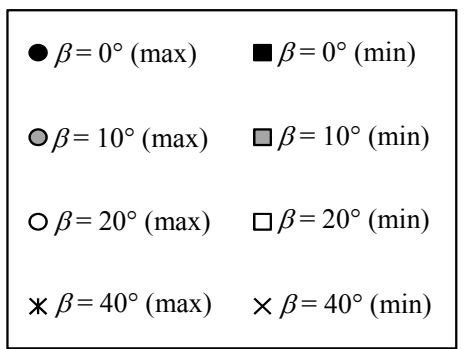

Fig. 5 Effect of $\beta_{x}$ on the aerodynamic coefficients $(h / a=1 / 2)$ : (a) $C_{L}$; (b) $C_{M x}$; (c) $C_{M y}$.

\subsection{Effect of Roof Slope on the Aerodynamic Coefficients}

Fig. 5 shows the effect of $\beta_{x}$ on the statistical values of $C_{L}, C_{M x}$ and $C_{M y}$ for $h / a=1 / 2$. As mentioned above, the negative peak value of $C_{L}$ becomes large in magnitude at $\theta \approx 90^{\circ}$. This peak value increases further with an increase in $\beta_{x}$ up to about $20^{\circ}$. This may be due to the increased flow velocity along the bottom surface, generating a large negative lift force. The effect becomes the greatest when $\beta_{x} \approx 20^{\circ}$. Such an increase in $\left|C_{L}\right|$ generates an increase in $\left|C_{M x}\right|$. The positive peak values of $C_{L}$ for $\theta<0^{\circ}$ increases with increasing $\beta_{x}$. In particular, the value of $C_{L}$ is rather large when $\theta \approx-45^{\circ}$. In such a wind direction case, the value of $C_{M x}$ is also rather large. On the other hand, the effect of $\beta_{x}$ on $C_{M y}$ is relatively small. Similar results were observed for $h / a=1 / 3$ and $1 / 6$.

\section{Discussion of Design Wind Force Coefficients}

\subsection{Dynamic Load Effect}

In order to investigate the dynamic effect of flow turbulence on the column axial forces, the gust effect factor $G_{f}$, defined as the ratio of the maximum or the minimum axial force to the mean value induced in the column, was computed. Fig. 6 shows the results for $G_{f}$ plotted against the mean reduced axial force $N_{\text {mean }}^{*}$, in which W.D.1 and W.D.2 represent the wind direction ranges of $\theta=0^{\circ}-45^{\circ}$ and $45^{\circ}-90^{\circ}$, respectively. When the value of $\left|N_{\text {mean }}^{*}\right|$ is small, $G_{f}$ generally exhibits a large value. However, as $\left|N_{\text {mean }}^{*}\right|$ increases, the values of $G_{f}$ collapse into a narrow range around $G_{f}=2.0$, which correspond to a peak factor of $g_{f} \approx 2.5$, based on the quasi-steady assumption, i.e., $G_{f} \approx\left(1+g_{f} \times I_{u H}\right)^{2}$ $=(1+2.5 \times 0.17)^{2}$. The value of $g_{f} \approx 2.5$ is somewhat 


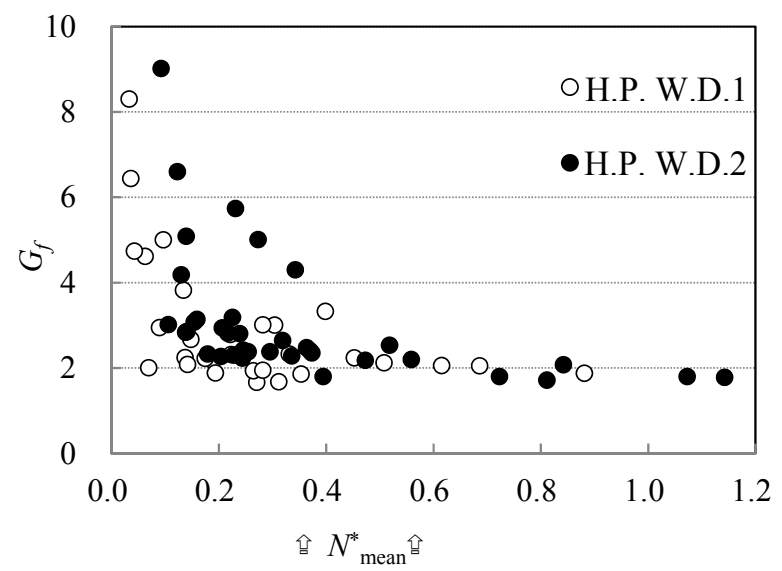

Fig. 6 Gust effect factor based on the load effect.

smaller than that for gable, troughed and mono-sloped roofs, which is approximately 3.0 [6]. This difference may be due to the effect of flow separation from the leading edges of the roof on the wind loads. That is, the turbulence induced by the flow separation seems lower for H.P. roofs than for the other roofs. In the following sections, the value of $G_{f}=2.0$ is used for evaluating the design wind force coefficients, providing the equivalent static wind loads.

\subsection{Design Wind Force Coefficients for Roofs with No Slope}

For the purpose of simplicity, the design wind force coefficients on the roof are specified by two uniformly distributed values, $C_{N W}{ }^{*}$ and $C_{N L}{ }^{*}$, over the windward and leeward halves (Fig. 7). Such a definition is the same as that used in the AS/NZ Standard [1]. The wind force coefficients can be evaluated based on the following procedure that was proposed by Uematsu et al. [6] for gable, troughed and mono-sloped roofs.

Step 1: The basic values of $C_{N W}{ }^{*}$ and $C_{N L}{ }^{*}$, denoted

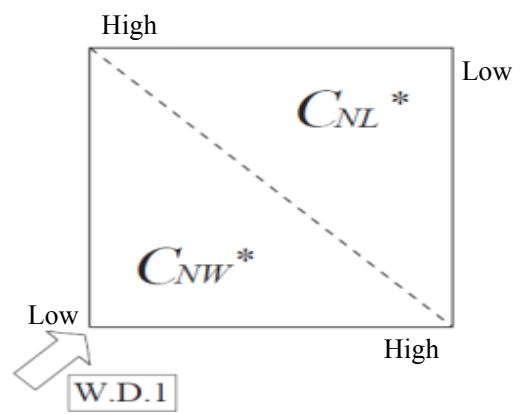

as $C_{N W 0}$ and $C_{N L 0}$, are determined from a combination of the lift coefficient $\left(C_{L}\right)$ and the moment coefficient $\left(C_{M y}\right.$ or $C_{M x}$ ) that produces the maximum load effect when $\theta=0^{\circ}$ or $90^{\circ}$. The $C_{N W 0}$ and $C_{N L 0}$ values may be given by the following equations $[6,14,15]$ :

$$
\begin{array}{r}
\theta=0^{\circ}: C_{N W 0}=-C_{L}-2 C_{M y} \\
C_{N L 0}=-C_{L}+2 C_{M y} \\
\theta=90^{\circ}: C_{N W 0}=-C_{L}+2 C_{M x} \\
C_{N L 0}=-C_{L}-2 C_{M x}
\end{array}
$$

Step 2: Considering that the axial force induced in the column may become the maximum for an oblique wind, a correction factor $\gamma$ is introduced: $\gamma$ is defined as the ratio of the actual peak force for a wind direction range of $\theta=0^{\circ}$ to $45^{\circ}$ (W.D.1) or $\theta=45^{\circ}$ to $90^{\circ}$ (W.D.2) to that computed from the $C_{N W 0}$ and $C_{N L 0}$ values for $\theta=0^{\circ}$ or $90^{\circ}$. Indeed, the value of $\gamma$ ranges from 1.0 to 1.2 in most cases. When the calculated value of $\gamma$ is less than 1.0, it is replaced by 1.0.

Step 3: The design wind force coefficients, $C_{N W}{ }^{*}$ and $C_{N L}{ }^{*}$, which give the equivalent static wind loads, are provided by the following equations:

$$
\begin{gathered}
C_{N W}{ }^{*}=\frac{\gamma C_{N W 0}}{G_{f}} \\
C_{N L}{ }^{*}=\frac{\gamma C_{N L 0}}{G_{f}}
\end{gathered}
$$

The most important problem for specifying the design wind force coefficients is how to combine the values of $C_{L}$ and $C_{M y}$ in Eqs. (4) and (5) and $C_{L}$ and $C_{M x}$ in Eqs. (6) and (7). The wind force coefficients $C_{N W 0}$ and $C_{N L O}$ should be determined so that they produce the maximum load effect. Fig. 8a shows a phase-plane representation of the $C_{M y}-C_{L}$ relation for $h / a$ $=1 / 3$ when $\theta=0^{\circ}$. There exists a positive correlation

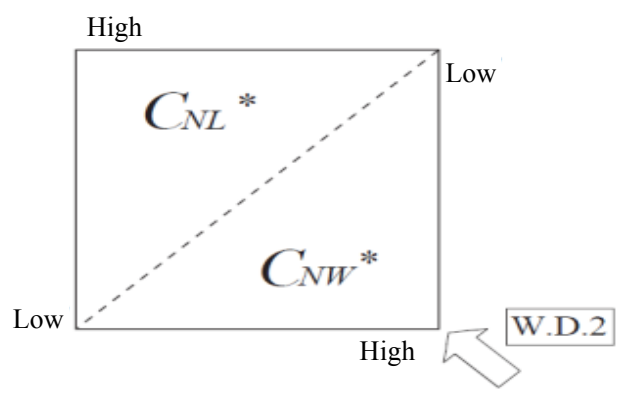

Fig. 7 Roof division for the specification of wind force coefficients. 


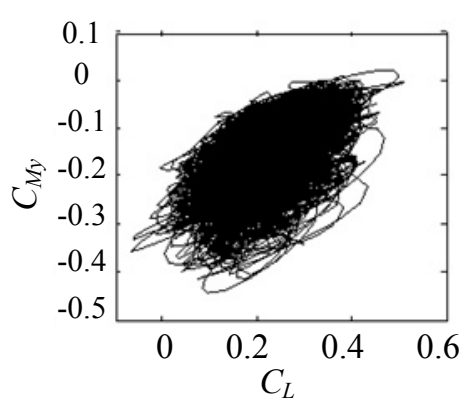

(a)

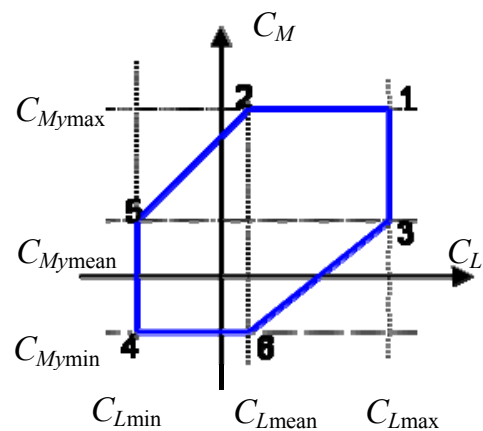

(b)

Fig. 8 Phase-plane representation of the $C_{M y}-C_{L}$ relation for a solid roof $\left(h / a=1 / 3, \theta=0^{\circ}\right)$ : (a) experimental result; (b) model of the envelope of the trajectory.

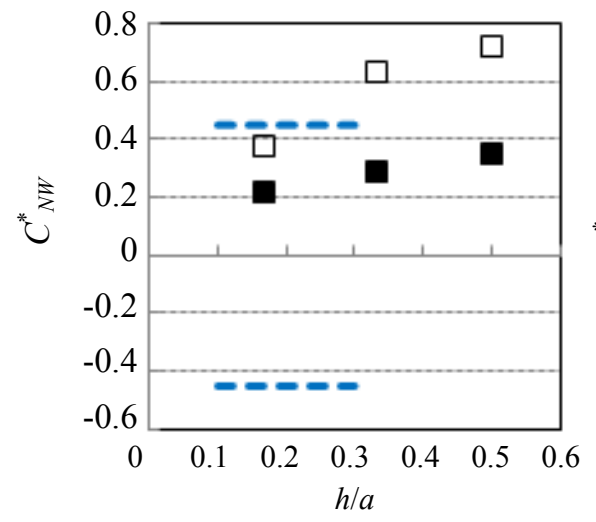

(a)

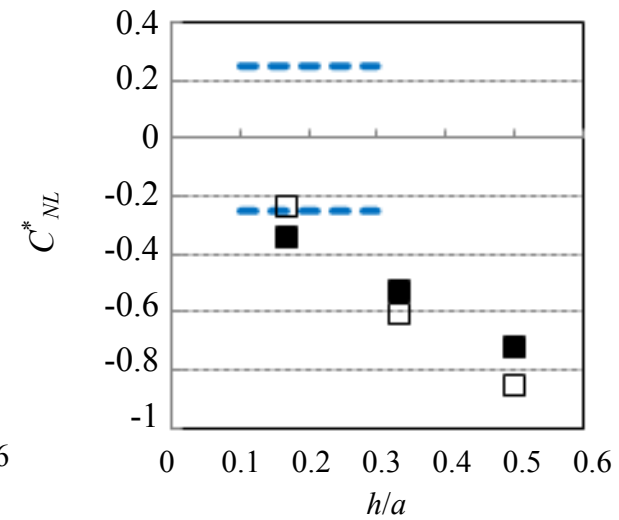

(b)

Fig. 9 Wind force coefficients $C^{*}{ }_{N W}$ and $C^{*}{ }_{N L}$ (W.D.1): (a) $C_{N W}{ }^{*}$; (b) $C_{N L}{ }^{*}$.

between these two coefficients. The correlation becomes poorer as the $h / a$ ratio increases. Envelop of the $C_{M y}-C_{L}$ trajectory is approximated by a hexagon, as shown in Fig. 8b. The critical condition that produces the maximum load effect may be given by a combination of $C_{L}$ and $C_{M y}$ at one of these six apexes. In order to investigate the load combination effects, the axial forces induced in the columns were computed for the six combinations of $C_{L}$ and $C_{M y}$ (Apexes 1-6). Focus is on the two Load Cases A and B, producing the maximum tension and compression in the columns, respectively. Substituting the corresponding $C_{L}$ and $C_{M y}$ values into Eqs. (4) and (5), the values of $C_{N W 0}$ and $C_{N L 0}$ for each load case are obtained. The same procedure is taken for $\theta=90^{\circ}$, in which $C_{L}$ and $C_{M x}$ are considered.

The results of $C_{N W}{ }^{*}$ and $C_{N L}{ }^{*}$ for W.D.1 and W.D.2 are shown in Figs. 9 and 10, respectively. In the figures, the specified values in the AS/NZ Standard [1] are also shown. The standard provides two values of wind force coefficients (expressed as "positive" and "negative") for each of the windward and leeward halves. The range of $h / a$ is limited from 0.1 to 0.3 . The proposed wind force coefficients, $C_{N W}{ }^{*}$ and $C_{N L}{ }^{*}$, do not necessarily agree with the AS/NZ specifications, although a good agreement can be seen for some cases. Similar features were observed for gable, troughed and mono-sloped roofs in the authors' previous study [6]. Such a difference may be due to a difference in the criteria for specifying the wind force coefficients.

Next, the axial forces induced in the columns were computed by using $C^{*}{ }_{N W}$ and $C^{*}{ }_{N L}$ and compared with those predicted from the AS/NZ specifications. Fig. 11 


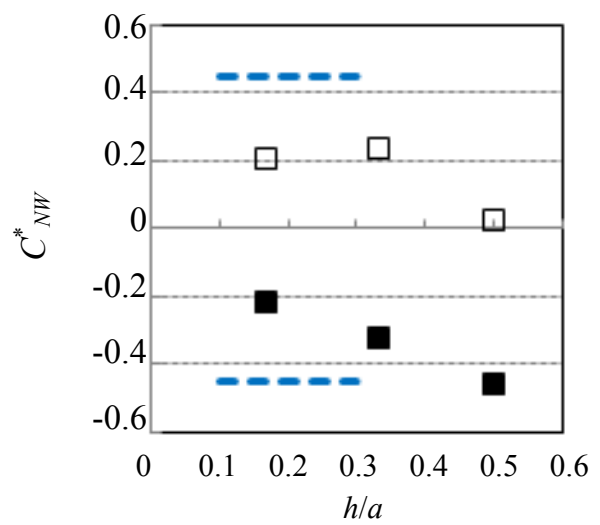

(a)

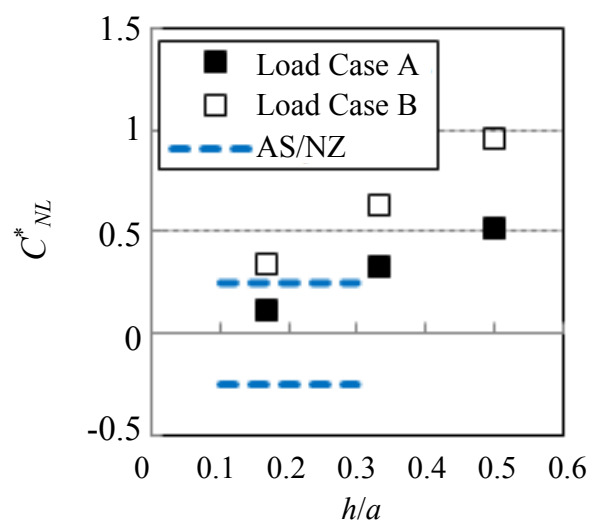

(b)

Fig. 10 Wind force coefficients $C^{*}{ }_{N W}$ and $C^{*}{ }_{N L}$ (W.D.2): (a) $C_{N W}{ }^{*}$; (b) $C_{N L}{ }^{*}$.

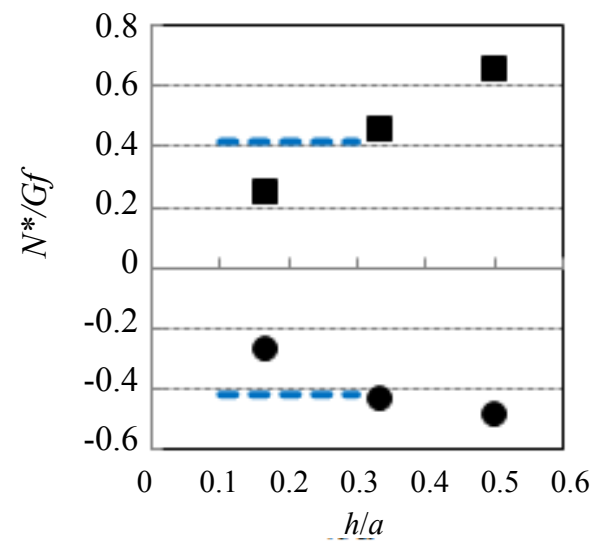

(a)

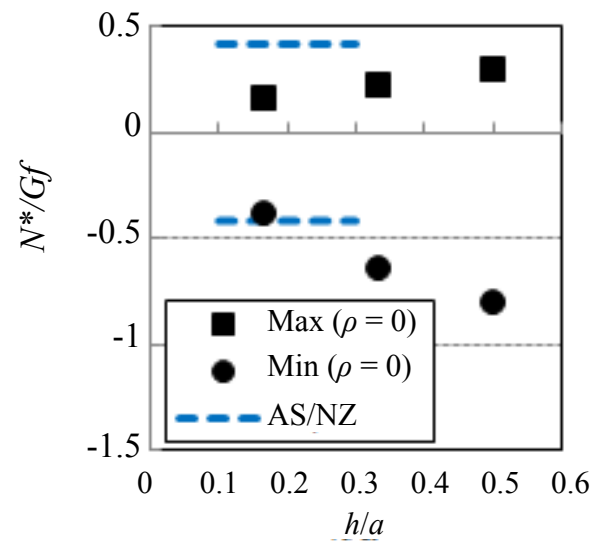

(b)

Fig. 11 Reduced axial forces induced in the columns: (a) W.D.1; (b) W.D.2.

shows the results, in which the ordinate is the non-dimensional axial force $N^{*}$ divided by $G_{f}$. As mentioned above, the AS/NZ Standard generally provides four combinations of the wind force coefficients on the windward and leeward halves. The maximum and minimum axial forces among them are shown Fig. 11. It is interesting to note that these values are consistent with the present results for Load Cases A and $\mathrm{B}$ for $h / a=0.1$ to 0.3 , despite a difference in the wind force coefficients, as shown in Figs. 9 and 10.

\subsection{Effect of Roof Slope on Wind Force Coefficients}

The wind force coefficients $C_{N W}{ }^{*}$ and $C_{N L}{ }^{*}$ for $\beta_{x}>0^{\circ}$ were also obtained through the above-mentioned procedure. Because the roof is not symmetric with respect to the $x$-axis, the wind direction range W.D.1 should be $\theta=-45^{\circ}$ to $45^{\circ}$. Furthermore, another wind direction range of $\theta=-45^{\circ}$ to $-90^{\circ}$ (W.D.3) should be considered. The results on $C_{N W}{ }^{*}$ and $C_{N L}{ }^{*}$ for these wind direction ranges are plotted in Figs. 12-14. As might be expected from the results in Fig. 5, the values of $C_{N W}{ }^{*}$ and $C_{N L}{ }^{*}$ generally increase in magnitude with increasing $\beta_{x}$ up to about $20^{\circ}$ for W.D.1 and W.D.2. Some coefficients further increase and the others decrease in magnitude with increasing $\beta_{x}$ beyond $20^{\circ}$. The solid lines in the figures show the simplified models for $C_{N W}{ }^{*}$ and $C_{N L}{ }^{*}$ as a function of $\beta_{x}$, which can be used for the design of H.P. free roofs.

\section{Conclusions}

The wind force coefficients for designing the structural frames of hyperbolic paraboloid free roofs were proposed based on a wind tunnel experiment with rigid models made of nylon resin by using laser 


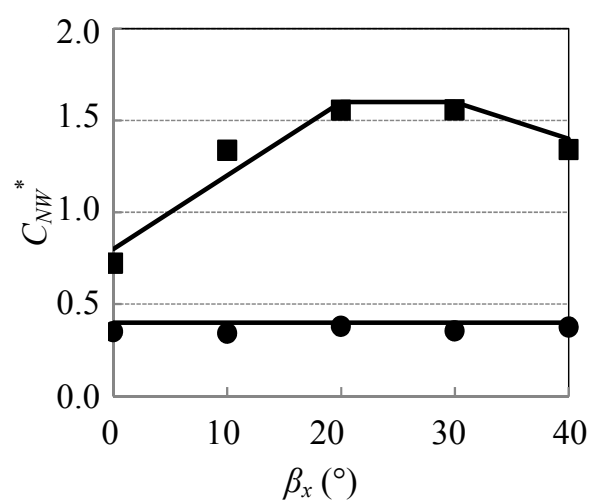

(a)

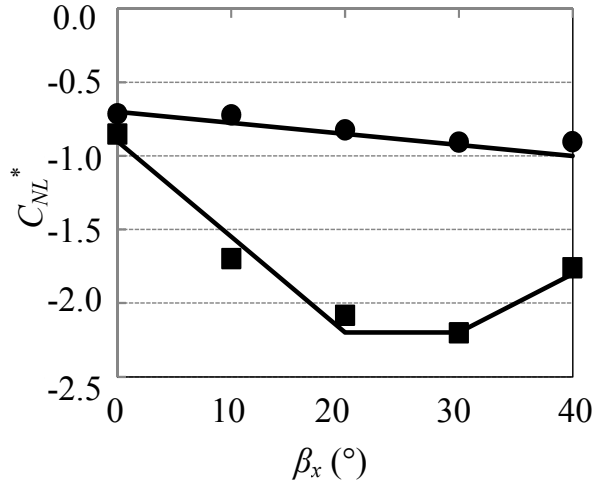

(b)

Fig. 12 Effect of $\beta_{x}$ on $C_{N W}{ }^{*}$ and $C_{N L}{ }^{*}\left(h / a=1 / 2\right.$, W.D.1): (a) $C_{N W}{ }^{*}$; (b) $C_{N L}{ }^{*}$.

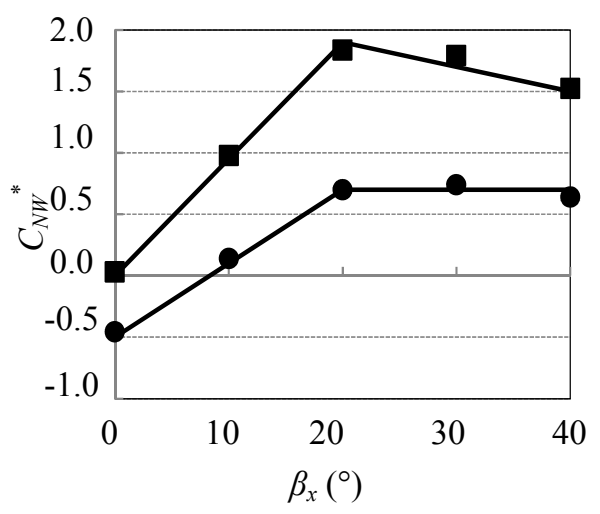

(a)

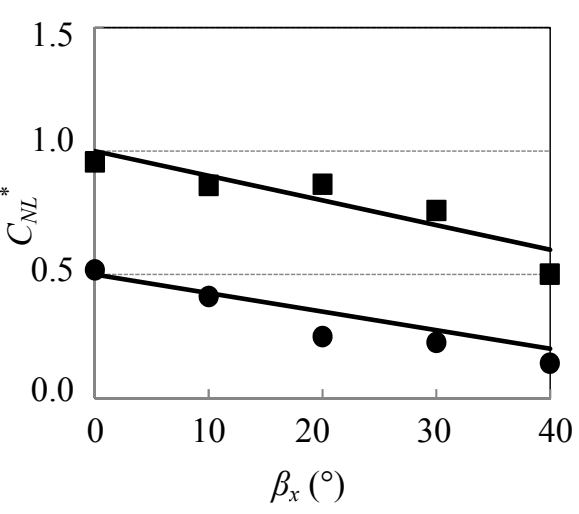

(b)

Fig. 13 Effect of $\beta_{x}$ on $C_{N W}{ }^{*}$ and $C_{N L}{ }^{*}\left(h / a=1 / 2\right.$, W.D.2): (a) $C_{N W}{ }^{*}$; (b) $C_{N L}{ }^{*}$.

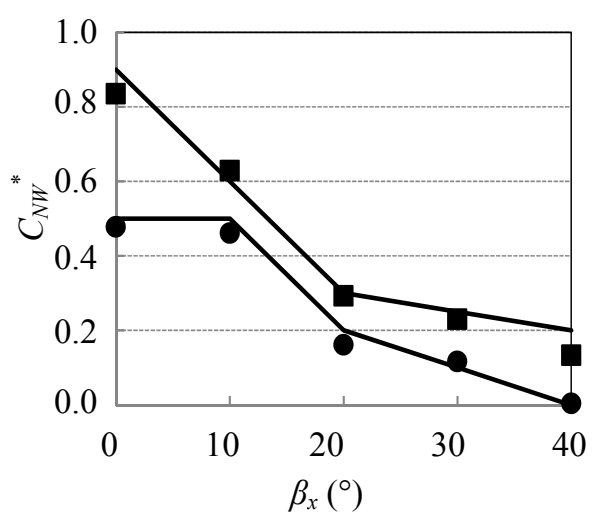

(a)

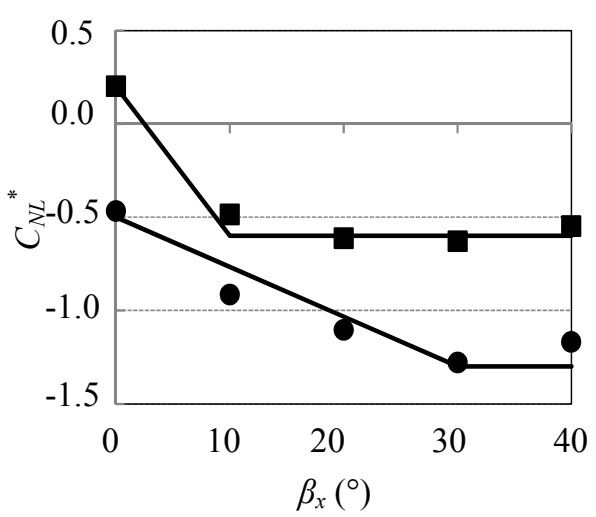

(b)

Fig. 14 Effect of $\beta_{x}$ on $C_{N W}{ }^{*}$ and $C_{N L}{ }^{*}\left(h / a=1 / 2\right.$, W.D.3): (a) $C_{N W}{ }^{*}$; (b) $C_{N L}{ }^{*}$.

lithography. The overall aerodynamic forces and moments acting on the roofs with $h / a=1 / 2,1 / 3$ and $1 / 6$ were measured with a six-component force balance in a turbulent boundary layer. The roof sloop $\beta_{x}$, obtained by raising one of the higher corners and lowering the opposite corner, was changed from $0^{\circ}$ to $40^{\circ}$. The effects of $h / a$ and $\beta_{x}$ on the aerodynamic forces and moments were investigated.

Based on the results, the design wind force coefficients were discussed from the viewpoint of load effect. The axial forces induced in the columns were regarded as the load effect for discussing the design wind loads, assuming that the roof was rigid and simply supported by four corner columns. The design 
wind force coefficients, represented as uniformly distributed values on the windward and leeward halves of the roof, were proposed as a function of $h / a$ and $\beta_{x}$.

In the membrane roof case, the deformation and oscillation may affect the wind loads. Furthermore, the other roof supporting systems different from that considered here may be used in practical designs, e.g., "post and guy cable" system. The application of the wind force coefficients proposed in the present paper to such cases should be investigated. These are the subjects of future studies.

\section{Acknowledgments}

A part of the present study is financially supported by Nohmura Foundation for Membrane Structure's Technology. Thanks are also due to Mr. H. Sakurai, who was then a graduate student at Tohoku University, for help with experiments.

\section{References}

[1] Standards Australia, Australia/New Zealand Standard, AS/NZ 1170.2, 2011.

[2] A.J. Dutt, Wind loading on a pyramidal roof structure, International Journal of Space Structures 1 (1985) 105-110.

[3] A.J. Dutt, Wind pressure distribution on multiple hyperbolic paraboloid shell roof building, International Journal of Space Structures 2 (1986) 49-54.

[4] A.J. Dutt, Wind loading on a "saw tooth" multiple hyperbolic paraboloid shell roof, International Journal of Space Structures 3 (1988) 43-50.

[5] Y. Uematsu, T. Stathopoulos, Wind loads on free-standing canopy roofs: A review, Journal of Wind Engineering, JAWE (Japan Association for Wind Engineering) 95 (2003) 245-256.

[6] Y. Uematsu, E. Iizumi, T. Stathopoulos, Wind force coefficients for designing free-standing canopy roofs, Journal of Wind Engineering and Industrial Aerodynamics 95 (2007) 1486-1510.

[7] J. Beutler, Beitrag zur statischen windbelastung von seilnetzwerken - Ergebnisse von windkanaluntersuchungen, hanging roofs (Colloquium on hanging roofs, continuous metallic shell roofs and superficial lattice roofs), in:
Proceedings of the IASS (Iinernational Assocoation for Shell and Spatial Structures) Colloquium on Hanging Roofs, Continuous Metallic Shell Roofs and Superficial Lattice Roofs, Paris, North-Holland Publishing Company, 1963, pp. 76-86.

[8] P.K.F. Pun, C.W. Letchford, Analysis of a tension membrane hypar roof subjected to fluctuating wind loads, in: Proceedings of Third Asia-Pacific Symposium on Wind Engineering, Hong Kong, 1993, pp. 741-746.

[9] T. Kaseya, A. Okada, N. Miyasato, S. Hiroishi, Y. Nagai, S. Yoshino, et al., Study on wind response on H.P.-shaped membrane roof, Part 1: Effect of Reynolds number on wind pressure distribution, in: Summaries of Technical Papers of Annual Meeting, Architectural Institute of Japan, 2013, pp. 181-182. (in Japanese)

[10] R. Nakagawa, A. Okada, N. Miyasato, S. Hiroishi, Y. Nagai, S. Yoshino, et al., Study on wind response on H.P.-shaped membrane roof, Part 2: Effect of Reynolds number on static and dynamic response, in: Summaries of Technical Papers of Annual Meeting, Architectural Institute of Japan, 2013, pp. 183-184. (in Japanese)

[11] S.J. Gumley, Panel Loading Mean Pressure Study for Canopy Roofs, OUEL report No.1380/81, Department of Engineering Science, University of Oxford, 1981.

[12] B. Natalini, J.O. Marighetti, M.B. Natalini, Wind tunnel modelling of mean pressures on planar canopy roof, Journal of Wind Engineering and Industrial Aerodynamics 90 (2002) 423-439.

[13] F. Takeda, T. Yoshino, Y. Uematsu, Wind Force Coefficients for the Design of Hyperbolic Paraboloid Shaped Free Roofs, Research reports on membrane structures 2012, The Membrane Structures Association of Japan, 2013, pp. 79-92. (in Japanese)

[14] Y. Uematsu, F. Arakatsu, S. Matsumoto, F. Takeda, Wind force coefficients for the design of hyperbolic paraboloid free roof, in: Proceedings of the Seventh Asia-Pacific Conference on Wind Engineering, Taipei, Taiwan, 2009. (CD-ROM)

[15] Y. Uematsu, Y. Miyamoto, H. Sakurai, E. Gavanski, Wind Force Coefficient for Designing Porous Canopy Roofs, Part 2: H.P.-Shaped Roof, Research reports on membrane structures 2012, The Membrane Structures Association of Japan, 2013, pp. 71-78. (in Japanese)

[16] F. Takeda, T. Yoshino, Y. Uematsu, Wind force coefficients for the design of a hyperbolic paraboloid free roof, in: Proceeding of the IASS (International Association for Shell and Spatial Structures) Symposium, Shanghai, China, 2010, pp. 1698-1709. 